\title{
Development and Implementation of a Zika Virus Disease Response Protocol at a Large Academic Medical Center
}

\author{
Rossana Rosa, MD; Lilian M. Abbo, MD; Girish Kapur, MD, MPH; Peter Paige, MD; \\ Reynald Jean, MD, MPH; Edhelene Rico, BS, MPH; Abdul M. Memon, MD
}

\section{ABSTRACT}

The rapid spread of Zika virus represents a threat to public health and demands significant preparation from hospitals and health care systems. Establishment of procedures for the identification of cases of Zika virus infection is a fundamental aspect of response planning. We describe the steps taken in the development and implementation of a protocol for the diagnosis and management of suspected cases of Zika virus infection in a large academic medical center. (Disaster Med Public Health Preparedness. 2017;11:256-258)

Key Words: Zika, quality of health care, health care facilities, manpower, and services

Z ika virus (ZIKV) is an arthropod-borne virus (arbovirus) in the genus Flavivirus, first identified in a rhesus monkey in the Zika forest in Uganda in $1947 .{ }^{1}$ Before 2007, reports of human infection were rare. In May 2015, Brazil reported the first cases of ZIKV in the Americas. In 12 months the infection had spread in at least 35 countries and territories including Puerto Rico. ${ }^{2}$ The main vector of ZIKV, Aedes aegypti, also transmits dengue, chikungunya, and yellow fever ${ }^{3}$ and is found in 11 states in the continental United States, including Florida. ${ }^{4}$ Sexual transmission from male to female through vaginal sex ${ }^{5}$ and from male to male through anal sex has been reported. ${ }^{6}$ Infection during pregnancy is associated with poor fetal outcomes. ${ }^{7}$

On January 15, 2016, the Centers for Disease Control and Prevention (CDC) issued a level 2 travel alert to Puerto Rico and the countries and territories where transmission of ZIKV was ongoing, including special recommendations for pregnant women. ${ }^{8}$ On February 3, 2016, Florida Governor Rick Scott declared a State of Emergency in the 4 counties that had cases of ZIKV infection. ${ }^{9}$ As of May 20, 2016, there were 116 imported cases of ZIKV in Florida. Forty-six of those cases occurred in Miami-Dade County. ${ }^{10}$ Miami is a major international hub for transportation and commerce and the largest port of entry into the United States from Latin America. Jackson Health System (JHS) operates the safety net hospitals of Miami-Dade County, serving an ethnically diverse population of approximately 2.8 million residents, with a large proportion of them having friends and relatives traveling from countries currently affected by the ZIKV epidemic. $^{2}$
At JHS, our clinical and administrative leadership recognized early on the need to develop a protocol that included best practices and guidance to appropriately diagnose and refer for testing patients with suspected ZIKV infection and to educate patients and employees about keys aspects of ZIKV. In the present report, we aimed to describe the steps taken in the development and implementation of JHS's multidisciplinary clinical and laboratory protocol for the diagnosis and management of suspected cases of ZIKV infection.

\section{CREATION OF THE TASK FORCE}

The first step in the development of the JHS Clinical Protocol for Suspected Zika Virus Infection (hereafter referred to as the protocol) was to create a task force with representatives from key stakeholders and departments chaired by our chief medical officer for disaster and emergency preparedness. Members of the task force included chief medical officers; the director of operations; chiefs of emergency medicine, ambulatory care, and infection prevention and control; specialists in infectious diseases, obstetrics, and pediatrics; nursing leadership; corrections services leadership; and representatives from public relations, the microbiology laboratory, environmental services, and the Florida Department of Health in Miami-Dade County (DOH-Miami-Dade). Communications to the appropriate departments were done through the offices of the chief medical officers via e-mail.

\section{DEVELOPMENT OF THE CLINICAL PROTOCOL}

The protocol was designed following the epidemiological and clinical information provided by the CDC 
and the DOH-Miami-Dade. The workflow was structured to maximize the opportunities for early identification of patients at risk for ZIKV infection starting at the point of entry to JHS and also to guide health care providers through the different steps in the recognition, testing, and follow-up of patients with suspected ZIKV infection. Considerations for the procurement and transportation of biological samples were also standardized based on continuous updated guidance from the DOH-Miami-Dade and the CDC.

The first steps in the protocol were as follows: (1) identification of patients who had recently traveled to areas with active transmission, (2) identification of patients with clinical findings characteristic of ZIKV infection, and (3) referral to appropriate triage area and notification to nursing managers.

The protocol provided guidance on differential diagnoses to be considered, such as dengue and chikungunya. Diagnostic testing for alternative etiologies was left at the discretion of each clinician and the DOH-Miami-Dade.

A direct phone number was provided by the DOH-MiamiDade for determination of whether a patient qualifies for ZIKV testing. Written and graphical instructions for filling out the required forms were also included. Step-by-step instructions on how to screen patients and request collection of biological samples for testing through the electronic medical record were outlined and updated weekly or biweekly as needed.

The protocol also provided guidance for outpatient follow-up and instructions for screening risk factors and prevention of sexual transmission. It was agreed that the DOH-Miami-Dade would notify the requesting health care provider of positive test results and fax positive and negative results to the hospital's microbiology laboratory. The health care provider would then notify the patient. Our microbiology laboratory received confirmatory results for all patients tested and notified Infection Control and the task force leadership weekly.

\section{Pregnant Women}

Because of the association between ZIKV and fetal malformations, special considerations are needed when caring for pregnant women. Testing and sample transportation are done by following the same steps as for the general patient population, and processes for submission of placental and fetal tissues for ZIKV testing were established. A specialist in gynecology and obstetrics was designated for referral of patients deemed to require serial obstetric ultrasounds, and the contact information for this specialist was provided in the protocol. Laboratory testing of the newborn (placenta tissue, cord blood) and mother (if not previously done) after delivery was also coordinated between the departments of obstetrics and pediatrics, the microbiology laboratory, and the $\mathrm{DOH}$ Miami-Dade.

\section{Pediatric Patients}

Owing to the rapid updating of information regarding the evaluation and testing of infants with possible ZIKV infection, the decision was made to instruct the pediatric and obstetric health care providers to follow the latest version of the "Interim Guidelines for Health Care Providers Caring for Infants and Children with Possible Zika Virus Infection" ${ }^{11}$ and "Zika Virus: Collection and Submission of Fetal Tissues for Zika virus testing"12 found on the CDC's website.

\section{DISSEMINATION OF PROTOCOL}

Creation and approval of the protocol was done promptly following the declaration of the Zika public health emergency in the State of Florida. The task force met biweekly to keep the protocol up-to-date. A "Zika Virus" folder was created in the hospital's intranet containing the protocol itself and also updated information issued by the $\mathrm{CDC}$ and the $\mathrm{DOH}$ Miami-Dade. A template of the latest version of the protocol is available in the online data supplement.

Support from the executive leadership, close collaboration with the DOH-Miami-Dade, and designating a team leader with vast experience in emergency preparedness were keys to the success of rapidly deploying an effective team collaboration and implementing the protocol in all clinical areas where potentially infected patients need to be screened and tested. The main challenges we encountered were the rapid pace at which information is being disseminated in social media, creating a unified protocol for multiple points of entry into the health system, and maintaining an updated protocol as new information is received from government agencies.

\section{CONCLUSION}

In a large health system, a unified protocol allows the multiple clinical areas to channel suspected patients into a single pathway to identify almost all at-risk patients. As our knowledge about the neurotropism and fetal effects of ZIKV continues to evolve, health care systems proactively need to prepare personnel and resources, coordinate education, and implement protocols to tackle these continuous threats to our public health.

\section{About the Authors}

Department of Medicine, Jackson Memorial Hospital, Miami, Florida (Dr Rosa); Division of Infectious Diseases, University of Miami Miller School of Medicine, Miami, Florida (Drs Rosa and Abbo); Department of Infection Control and Antimicrobial Stewardship, Jackson Health System, Miami, Florida (Dr Abbo); Department of Emergency Medicine, Jackson Memorial Hospital, Miami, Florida (Dr Kapur); Chief Medical Officer, Jackson Health System, Miami, Florida (Dr Paige); Florida Department of Health in Miami-Dade County (Dr Jean and Ms Rico); and Division of Disaster and Emergency Preparedness, Jackson Health System, Miami, Florida (Dr Memon).

Correspondence and reprint requests to Abdul M Memon MD, FACP, FACEP, Jackson Health System, Institute Annex Building Room 336, Miami, Fl 33136-1096 (e-mail: amemon@jhsmiami.org) or Rossana Rosa, MD, Jackson Health System, Central Building, Room 766, Miami, Fl 33136-1096 (e-mail: rossana.m.rosa@ gmail.com) 


\section{Acknowledgments}

Ms Elisha Moultrie provided administrative assistance to the Zika Task Force.

\section{Supplementary material}

To view supplementary material for this article, please visit http://dx.doi.org/ $10.1017 / \mathrm{dmp} .2016 .116$

Published online: July 19, 2016.

\section{REFERENCES}

1. Dick GW, Kitchen SF, Haddow AJ. Zika virus. I. Isolations and serological specificity. Trans R Soc Trop Med Hyg. 1952;46:509-520.

2. Zika Travel Information. Centers for Disease Control and Prevention website. http://wwwnc.cdc.gov/travel/page/zika-information. Published 2016. Updated May 12, 2016. Accessed May 14, 2016.

3. Marchette NJ, Garcia R, Rudnick A. Isolation of Zika virus from Aedes aegypti mosquitoes in Malaysia. Am J Trop Med Hyg. 1969; 18:411-415

4. Surveillance and Control of Aedes aegypti and Aedes albopictus in the United States. Centers for Disease Control and Prevention website. http://www.cdc.gov/chikungunya/resources/vector-control.html. Published 2015. Updated March 29, 2016. Accessed March 30, 2016.

5. Hills SL, Russell K, Hennessey M, et al. Transmission of Zika virus through sexual contact with travelers to areas of ongoing transmission - continental United States, 2016. MMWR Morb Mort Wkly Rep. 2016;65:215-216.

6. Deckard DT, Chung WM, Brooks JT, et al. Male-to-male sexual transmission of Zika virus - Texas, January 2016. MMWR Morb Mort Wkly Rep. 2016;65:372-374.

7. Rasmussen SA, Jamieson DJ, Honein MA, et al. Zika virus and birth defects - reviewing the evidence for causality. N Eng J Med. 2016;374: 1981-1987.

8. CDC issues interim travel guidance related to Zika virus for 14 Countries and Territories in Central and South America and the Caribbean. Centers for Disease Control and Prevention website. http://www.cdc.gov/ media/releases/2016/s0315-zika-virus-travel.html. Published January 15, 2016. Accessed March 2, 2016.

9. Gov. Rick Scott directs public health emergency in four counties for Zika Virus. Florida Governor Rick Scott website. http://www.flgov.com/ 2016/02/03/gov-rick-scott-directs-public-health-emergency-in-four-countiesfor-zika-virus/. Published February 3, 2016. Accessed March 2, 2016.

10. Department of Health Daily Zika Update: Three New Travel-Related Cases Today. Florida Department of Health website. http://www. floridahealth.gov/newsroom/2016/05/052016-zika-update.html. Published May 20, 2016. Accessed May 21, 2016.

11. Clinical Guidance. Centers for Disease Control and Prevention website. http://www.cdc.gov/zika/hc-providers/clinical-guidance.html. Last updated April 25, 2016. Accessed June 17, 2016.

12. Zika Virus: Collection and Submission of Fetal Tissues for Zika Virus Testing. Centers for Disease Control and Prevention website. http://www. cdc.gov/zika/hc-providers/tissue-collection-submission.html. Last updated April 4, 2016. Accessed June 17, 2016. 